\title{
Farklı Yem Sunum Yöntemlerinin Siyah Alaca Buzağıların Büyüme Performansı, Yem Tüketimi ve Bazı Davranış Özellikleri Üzerine Etkileri
}

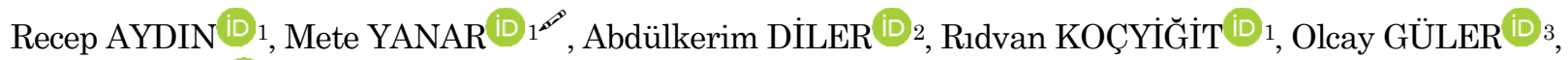 \\ Mehmet AVCI (D) 1
}

${ }^{1}$ Atatürk Üniversitesi, Ziraat Fakültesi, Zootekni Bölümü, ${ }^{2}$ Atatürk Üniversitesi Erzurum Meslek Yüksekokulu Bitkisel ve Hayvansal Üretim Bölümü, ${ }^{3}$ Atatürk Üniversitesi, Hınıs Meslek Yüksekokulu, Laborant ve Veteriner Sağlığı Bölümü

$\triangle:$ mtyanar@gmail.com

\section{ÖZET}

$\mathrm{Bu}$ çalışma, iki farklı yem sunum metodunun Siyah Alaca buzağılarının büyüme performansı, yem alımı, yemden yararlanma ve bazı davranış özellikleri üzerine etkilerini araştırmak üzere yürütülmüştür. Yem sunum grupları: 1. Kıyılmış kuru çayır otu ve kesif yem karışımı (KR), 2. Doğal formda kuru çayır otu ve kesif yemin iki ayrı yemlikte sunumu (AAR) şeklinde oluşturulmuştur. Toplam 25 adet Siyah Alaca buzağ (14' ü KR grubunda, 11'i AAR grubunda olmak üzere) araştırma materyali olarak kullanılmıştır. Araştırma sonuçları, buzağıların 3 ay $(\mathrm{P}<0.05)$ ve 6 ay $(\mathrm{P}<0.01)$ ağırlıkları ile sütten kesim-3 ay arası $(\mathrm{P}<0.05), 3-6$ ay arası $(\mathrm{P}<0.01)$ günlük canlı ağırlık artışlarının AAR lehine olduğunu ortaya koymuştur. Ayrıca doğum-6 aylık yaş periyodunda, AAR yöntemiyle beslenen buzağıların, KR ile yemlenenlere göre daha fazla $(\mathrm{P}<0.01)$ yem tükettikleri, ancak yemden yararlanma dereceleri bakımından muamele grupları arasında önemli bir farkın bulunmadığı da belirlenmiştir. İki farklı yemleme yönteminin, doğum-6 aylık yaş periyodunda göğüs derinliği ve göğüs çevresi gelişimi açısından AAR lehine önemli $(\mathrm{P}<0.05)$ etkileri olmuştur. Deneme süresince AAR yöntemiyle yemlenen buzağılarda daha az $(\mathrm{P}<0.01)$ oranda ayakta durma ve daha fazla $(\mathrm{P}<0.01)$ yem yeme ile su içme $(\mathrm{P}<0.05)$ davranışları gösterdikleri de saptanmıştır. Sonuç olarak, Siyah Alaca buzağılara doğal formda ve kesif yemden ayrı olarak verilen kaba yemin (AAR yöntemi), karışık rasyonla yemlemeye göre daha fazla ağırlık artışı ve yem tüketimine neden olduğu, yemden yararlanma derecesini olumsuz yönde etkilemediği tespit edilmiştir. Doğu Anadolu Bölgesi koşullarında yetiştirilen Siyah Alaca buzağılarını AAR yöntemiyle yemlemenin daha uygun olduğu sonucuna varılmıştır.
DOI:10.18016/ ksudobil.381128

\section{Makale Tarihçesi}

Received : 19.01.2018

Accepted : 19.02.2018

\section{Anahtar Kelimeler}

Siyah Alaca,

buzağ 1 ,

yem sunum yöntemleri, canlı ağırlık artışı, davranış özellikleri

\section{Araștırma Makalesi}

Effects of Different Feed Presentation Methods on the Growth Performance, Feed Intake and Some Behavioral Traits of Holstein Friesian Calves

\section{ABSTRACT}

This study was carried out to investigate effects of the two different feed presentation methods on the growth performance, feed intake, feed efficiency and some behavioral traits of Holstein Friesian calves. Feed presentation groups are: 1. Mixture of chopped dry hay and concentrate (MR), 2. Presentation of the concentrate and dry hay at natural form in two different feed bunks (SR). A total of 25 Holstein Friesian calves (14 heads in MR group; 11 heads in SR group) was used as research material. Results of the study revealed that 3 months $(\mathrm{P}<0.05)$ and 6 months $(\mathrm{P}<0.01)$ weights as well as weight gains between weaning and 3 months of age $(\mathrm{P}<0.05)$ and between 3 and 6 months $(\mathrm{P}<0.01)$ were in favor of SR. Additionally, calves fed according to $\mathrm{SR}$ method consumed higher $(\mathrm{P}<0.01)$ amount of feed compared to those in MR group, but it was also found out that there was no

\section{Article History}

Gelis : 19.01 .2018

Kabul : 19.02.2018

\author{
Keywords \\ Holstein Friesian, \\ calf, \\ feed presentation methods, \\ weight gain, \\ behavioral traits
}

\section{Research Article}


significant difference between treatment groups concerning feed efficiency values. Two different feed presentation methods had significant influence $(\mathrm{P}<0.05)$ on the gains of hearth depth and hearth girth in a period between birth and 6 months of age in favor of MR. It was also determined that calves fed according to SR method had lower $(\mathrm{P}<0.01)$ percentage of time spent for standing behavior and greater percentage of time spent for feeding $(\mathrm{P}<0.01)$ and drinking water $(\mathrm{P}<0.05)$ during the trial. As a result, presentation of the concentrate and dry hay at natural form in two different feeders (SR) to the Holstein Friesian calves resulted in higher weight gain as well as feed intake compared to MR feeding, and it did not affect adversely feed efficiency value. For that reasons, it was concluded that SR method was more appropriate for the Holstein Friesian calves raised under conditions of the Eastern Anatolian Region.

To Cite : Aydın R, Yanar M, Diler A, Koçyiğit R, Güler O, Avcı M. 2018. Farklı Yem Sunum Yöntemlerinin Siyah Alaca Buzağıların Büyüme Performansı, Yem Tüketimi ve Bazı Davranış Özellikleri Üzerine Etkileri. KSÜ Tarım ve Doğa Derg 21(4):607-614, DOI:10.18016/ksudobil.381128.

\section{GIRİŞ}

Pre-ruminant hayvanlarin fonksiyonel ruminant haline geçişinde, buzağıların kaba ve kesif yemleri tüketmeye başlamaları hayati bir öneme sahiptir (Coverdale ve ark. 2004). Buzağı rasyonlarında yer alacak kaba yemin içeriği ve miktarı yanı sıra, rumen içi koşullarını, uçucu yağ asitlerinin üretimini, rumen papillaların yapıları ile fonksiyonlarını etkilemesi bakımından kaba yemlerin parçacık büyüklüklerinin de ayrı bir önemi bulunmaktadır (Montoro ve ark., 2013). Çok kısa kaba yem partikül boyutlarına sahip rasyonlarla beslenen buzağllarda rumen asiditesi süratle artmakta, bu durum da ruminasyonun ve salya üretiminin azalmasına yol açabilmektedir. Ayrıca, aşırı derecede kısa doğranmış kaba yemler, bu hayvanlarda rumen papillalarında keratinizasyon insidensinde artışlara neden olmaktadır (Beharka ve ark., 1998). Bunun sonucu olarak, metabolik olarak aktif papilla dokusundaki azalma uçucu yă asitlerinin absorbsiyonunun da azalmasina yol açabilmektedir. Bununla birlikte, metabolik açıdan azalan aktif dokunun telafisi için, bu tip hayvanların rumen papillalarında dallanmalarin oluşmaya başladığı da Coverdale ve ark., (2004) tarafından ifade edilmiştir.

Süt sığırlarında beslenme davranışları, yemin sunuluş şeklinden de etkilenebilmektedir. Düvelere ve ineklere kaba ve kesif yemin ayrı ayrı verildiği yemleme sistemlerinde, kaba yemin sunum öncesi bu tarz bir uygulamanın konsantre yem tüketiminin hızla gerçekleşmesini teşvik ettiği Greter ve ark., (2010) ve Maekawa ve ark., (2002) tarafindan bildirilmiştir. Öte yandan, kaba ve kesif yemin karışım olarak yedirildiği düvelerde ve ergin sığırlarda, söz konusu yemlerin ayrı ayrı sunulduğu ve kaba yemin doğranmadan doğal olarak verildiği uygulamalara göre, günlük yem yeme süreleri daha uzun, ancak yem tüketim hızının daha düşük olduğu bildirilmiştir (DeVires ve von Keyserlingk, 2009; Maekawa ve ark., 2002). Yem alımı üzerine olan bu etkiler rumen sağlığını etkileyebilir. Ayrıca fiziksel etkinliği yetersiz selüloz tüketimi sonucunda da hayvanin rumeninde hılı bir fermentasyon ve bunu takiben $\mathrm{pH}$ daki hızlı düşüş ve artan asidosis riskinin de ortaya çıkması da olasıdır (Coverdale ve ark., 2004; Krause ve Oetzel, 2006).

Kaba ve kesif yemlerin yedirildiği buzağ programlarında, genellikle bu yemler ayrı ayrı yemliklerde buzağllara sunulur (Vasseur ve ark., 2010). Bununla birlikte, buzağllara kaba ve kesif yem maddelerinin serbest seçimli olarak buzağıların tüketim tercihine bırakıldığ serbest yemleme; toplam yem karışımı olarak adlandırılan öğütülmüş kaba yem ile kesif yemin karışımından oluşan rasyonlarla besleme; kaba yemin üzerine kesif yemin dökülerek sunulduğu yemleme yöntemi ve ayrıca kaba ve kesif yemin bir arada peletlenerek hazırlanan rasyonlarla yapılan alternatif yetiştirme yöntemleri de mevcuttur (Atwood ve ark., 2001; Miller-Cushon, 2013; Hassani ve ark., 2017).

Kaba yemin kıyılarak veya genellikle patoza vurularak ot samanı şeklinde (5 cm den kısa) kesif yemlerle birlikte karıştırılarak genç ve ergin sı̆̆ırların yemlemesinde kullanılma alışkanlığı yurdumuzun birçok bölgesinde yetiştiriciler arasında yaygın olarak yapılan bir uygulamadır (Bakır ve Demirel 2001; Hozman, 2014; Diler ve ark., 2016). Bununla beraber kaba yemin doğal formda buzağı başlatma ve büyütme yemlerinden ayrı olarak ta verildiği özel sektöre ve devlete ait sığırcılık işletmeleri de mevcuttur. Bu çalışma, ülkemiz koşullarında uygulamaları mevcut olan söz konusu iki ayrı yemleme sisteminin erkek ve dişi Siyah Alaca buzağılarda 6 aylık büyüme periyodun da büyüme ve gelişme performansları ile bazı davranış özellikleri üzerine etkilerini araştırmak amacıyla yapılmıştır.

\section{MATERYAL ve METOT}

Araştırmanın hayvan materyalini Atatürk 
Üniversitesi Ziraat Fakültesi Araştırma ve Uygulama Çiftliği Sığırcılık Şubesi'nde doğan Siyah Alaca buzağılar teşkil etmiştir. Araştırma materyali olarak deneme grubunda 14 (7 erkek, 7 dişi), kontrol grubunda ise 11 (5 erkek, 6 dişi) olmak üzere toplam 25 baş buzağ kullanılmıştır. Deneme süresince buzağılar yemliklerin ve suluğun bulunduğu bireysel buzağı bölmelerinde tutulmuşlardır.

$\mathrm{Bu}$ çalışmada, kıyılmış kaba yem ile kesif yem karıştırılarak bir yemlikte (KR) veya kaba ve kesif yem karıştırılmadan 2 ayrı yemlikte (AAR) olmak üzere 2 farklı şekilde buzağıların tüketimine sunulmuştur. Oluşturulan KR grubunda, kaba yem olarak buzağılara verilen kuru çayır otu, ot kesme makinesiyle ortalama $5 \mathrm{~cm}$ uzunlukta kıyılmıştır. KR grubundaki buzağılara doğum ile 3 aylık yaş arasında verilen rasyon \% 20'si kıyılmış kuru çayır otu ve \% 80'ni buzağ 1 başlatma yeminden, 3-6 aylık yaşlar arasında ise \% 30'u kıyılmış kuru çayır otu ve \% 70'i buzağı büyütme yeminin karıştırılmasıyla oluşturulmuştur. Diğer muamele grubundaki (AAR) buzağılara ise, kuru çayır otu kıyılmadan doğal formda olmak üzere kesif yemden ayrı olarak farklı yemliklerde sunulmuştur. Kuru çayır otu her iki grupta 0-3 aylık dönemde maksimum $0.750 \mathrm{~kg} /$ gün, 36 aylık dönemde de en çok $1.280 \mathrm{~kg} / \mathrm{gün}$ olarak verilmiş, kesif yem ise her iki grupta $3 \mathrm{~kg} /$ gün olarak sınırlandırılmıştır. Buzağılara günlük olarak verilen yem miktarları ile bir önceki günden yemlikte kalan yemler tartılarak günlük yem tüketimleri de belirlenmiştir. Araştırmada kullanılan yemlerin besin madde oranları Çizelge 1. de sunulmuştur.

Buzağılara doğum ağırlığının \% 8’i kadar sabit miktarlarda süt biberonla içirilerek 49 günde sütten kesilmişlerdir. Buzağıların doğum, sütten kesim, 3 ve 6 aylık yaşlardaki ağırlıkları (100 g. hassasiyette) hayvan baskülü yardımı ile tartılarak belirlenmiştir. Vücut gelişimlerini belirlemek üzere doğum ve 6 aylık yaşta buzağıların vücut uzunluğu, göğüs çevresi, göğüs derinliği, ön incik çevresi ve cidago yüksekliği gibi vücut ölçüleri alınmıştır.

Davranış parametreleri olarak; 1=Uzanma (Buzağının vücudu çevre veya altlıkla temasta), 2=Ayakta durma (Pasif olarak dikilme), 3=Yem yeme (Buzağının kafası yem kovasında) ve $4=\mathrm{Su}$ içme (Buzağının kafası su kovasında) davranışları belirlenmiştir. Davranış parametreleri haftada bir defa, saat 09:00-12:00 arasında her saat başı 15 dakikada bir kez olmak üzere ahır boyunca dolaşlarak ve bölmelerden en az $2.1 \mathrm{~m}$ uzaklıkta durularak kaydedilmiştir (Hunter ve Houpt 1989; Chua ve ark., 2002). Anlık örnekleme yöntemine göre örnekleme anında oluşan davranışlar kayıt edilerek bu özellikler için verilen kodlar sayılarak her bir davranış için harcanan zaman oransal olarak hesaplanmıştır (Martin ve Bateson 1993).

Araştırmada incelenen özellikler ile ilgili olarak elde edilen veriler SPSS istatistik paket programinda general linear modelde univariyet seçeneği kullanılarak analiz edilmiştir SPSS (2004). Veriler önce cinsiyet ve yem sunum metodu interaksiyonun da bulunduğu istatistiksel modele göre faktöriyel düzenlemede $2 \times 2$ tam şansa bağlı deneme planına göre analiz edilmiş, ancak ele alınan özelliklerde interaksiyonların önemsiz olması nedeniyle interaksiyon matematiksel modelden çıkarılmıştır.

Analizlerde kullanılan matematiksel model; $\mathrm{Y}_{\mathrm{ijk}}$ $=\mu+a_{i}+b_{j}+e_{i j k}$ şeklinde olup; $Y_{i j k}$ : Gözlem değeri, $\mu$ : Incelenen populasyonun ortalaması, $\mathrm{a}_{\mathrm{i}}$ : Yem sunum metodunu etkisi (KR, AAR), bj: Cinsiyetin etkisi (Dişi, Erkek), e $\mathrm{e}_{\mathrm{ijk}}$ : Ortalaması sıfır, varyansı $\sigma_{\mathrm{e}}^{2}$ olan şansa bağlı hatayı göstermektedir.

Çizelge 1. Araştırmada kullanılan yemlerin besin madde oranları (\%)

\begin{tabular}{lllll}
\hline Besin maddeleri & Süt & Buzağı Başlatma Yemi & Buzağı Büyütme Yemi & Kuru Çayır Otu \\
\hline Kuru madde & 12.0 & 88.0 & 88.0 & 88.0 \\
Ham protein & 3.8 & 18.0 & 17.0 & 7.1 \\
Ham yăg & 4.1 & 4.8 & 4.5 & 3.8 \\
Ham kül & 0.7 & 8.0 & 10.0 & 8.4 \\
Ham selüloz & - & 12.0 & 12.0 & 28.4 \\
\hline
\end{tabular}

\section{BULGULAR ve TARTIŞMA}

Farklı muamele gruplarındaki erkek ve dişi buzağıların çeşitli büyüme dönemlerinde saptanan canlı ağırlıklara ait en küçük kareler ortalamaları ve standart hataları Çizelge 2'de verilmiştir. Doğum ağırlıkları ve sütten kesim ağırlıkları bakımından KR ve AAR gruplarındaki buzağılar arasındaki farklar, istatistiksel olarak önemsiz bulunmuştur. Erkek ve dişi buzağıların doğum ağırlıkları arasındaki fark ise istatistiksel olarak önemli olup $(\mathrm{P}<0.05)$, erkek buzağılar dişilerden $4.76 \mathrm{~kg}$ daha fazla doğum ağırlığına sahip oldukları belirlenmiştir. Benzer şekilde, erkek buzağılarda cinsiyetin doğum ağırlığı artışı üzerine yaptığı önemli etkide bulunduğu Özlütürk ve ark., (2006) tarafından da bildirilmiştir.

KR ve AAR gruplarının 3 ay $(\mathrm{P}<0.05)$ ve 6 ay $(\mathrm{P}<0.01)$ ağırlıkları arasındaki farklar ise istatistiksel olarak önemli olup, doğal formda kuru çayır otu ve kesif yemin verildiği gruptaki buzağılar, KR grubundaki buzağılardan 3 aylık yaşta $6.63 \mathrm{~kg}, 6$ aylık yaşta 13.51 $\mathrm{kg}$ daha fazla canlı ağırlığa sahip oldukları saptanmıştır (Çizelge 2). $\mathrm{Bu}$ sonuçlar, AAR grubundaki Siyah Alaca buzağıların KR grubundakilere göre daha fazla yem tüketimine 
atfedilebilir. Benzer şekilde, doğal formda uzun saplı kuru yonca otu ile yemlenen Siyah Alaca buzağılarının, peletlenmiş yonca alan gruptakilere göre daha fazla canlı ağırlığa sahip oldukları Kincaid (1980) tarafından da bildirilmiştir. Öte yandan Plaza ve ark., (2009) karışık rasyonla yemlenen Siyah Alaca x Zebu melezi buzağıların 6. ay ağırlıklarının daha yüksek olduğunu rapor etmişlerdir.

Altı aylık yaş döneminde erkek buzağıların dişilere göre $7.6 \mathrm{~kg}$ daha ağır oldukları ve bu farkın da istatistiksel olarak $\quad(\mathrm{P}<0.05) \quad$ önemli olduğu belirlenmiştir. Doğu Anadolu Bölgesi koşullarında yetiştirilen Siyah Alaca buzağılar, 6. ay ağırlıkları bakımından karşılaştırıldığında, erkek ve dişilerin canlı ağırlıkları arasında önemli farkın $(4.8 \mathrm{~kg})$ olduğu Güler ve ark., (2003) tarafından da bildirilmiştir.

Sütten kesim öncesi ve sonrası günlük ağırlık artışlarına ait en küçük kareler ortalamaları ve standart hataları Çizelge 3’te sunulmuştur. Günlük ağırlık artışı bakımından sütten kesim öncesi muamele grupları arasında önemli bir farklılık gözlenmemiştir. Sütten kesim öncesi dönemde AAR ile KR grupları arasındaki günlük canlı ağırlık artışı bakımından önemli saptanamayan fark bakımından elde edilen sonuçlar Hill ve ark., (2010)'nın bulgularıly paralellik arz etmektedir.

Çizelge 2. Buzağıların büyümenin değişik dönemlerinde canlı ağırlıklarına (kg) ait en küçük kareler ortalamaları ve standart hataları

\begin{tabular}{llllll}
\hline & $\mathrm{N}$ & Doğum Ağırlığı & Sütten KesimAğırlığı & 3 Ay Ağırlığı & 6 Ay Ağırlığı \\
\hline & & $\bar{X} \pm S_{\bar{x}}$ & $\bar{X} \pm S_{\bar{x}}$ & $\bar{X} \pm S_{\bar{x}}$ & $\bar{X} \pm S_{\bar{x}}$ \\
\hline Genel ortalama & 25 & $36.64 \pm 0.97$ & $51.17 \pm 1.20$ & $78.00 \pm 1.76$ & $150.28 \pm 2.19$ \\
Yem Sunum Metotları & & OS & ÖS & $*$ & $* *$ \\
KR $^{1}$ & 14 & $36.09 \pm 1.29$ & $50.83 \pm 1.60$ & $74.67 \pm 2.34$ & $143.53 \pm 2.92$ \\
AAR $^{2}$ & 11 & $37.19 \pm 1.46$ & $51.51 \pm 1.83$ & $81.30 \pm 2.67$ & $157.04 \pm 3.33$ \\
Cinsiyet & & $*$ & ÖS & OS & $*$ \\
Dişi & 13 & $34.26 \pm 1.35$ & $49.97 \pm 1.65$ & $77.21 \pm 2.42$ & $146.48 \pm 3.01$ \\
Erkek & 12 & $39.02 \pm 1.42$ & $52.36 \pm 1.77$ & $78.77 \pm 2.58$ & $154.08 \pm 3.22$ \\
\hline
\end{tabular}

${ }^{*} \mathrm{P}<0.05$, ÖS: Önemli değil (P>0.05). ${ }^{1} \mathrm{KR}:$ Kıyılmış kaba yem ile kesif yemin karıştırılarak aynı yemlikte sunumu. ${ }^{2} \mathrm{AAR}$ :

Doğal formda kaba yemin, kesif yem ile karıştırılmadan ayrı yemliklerde sunumu.

Çizelge 3. Buzağılarda günlük ağırlık artışlarına (kg) ait en küçük kareler ortalamaları ve standart hataları

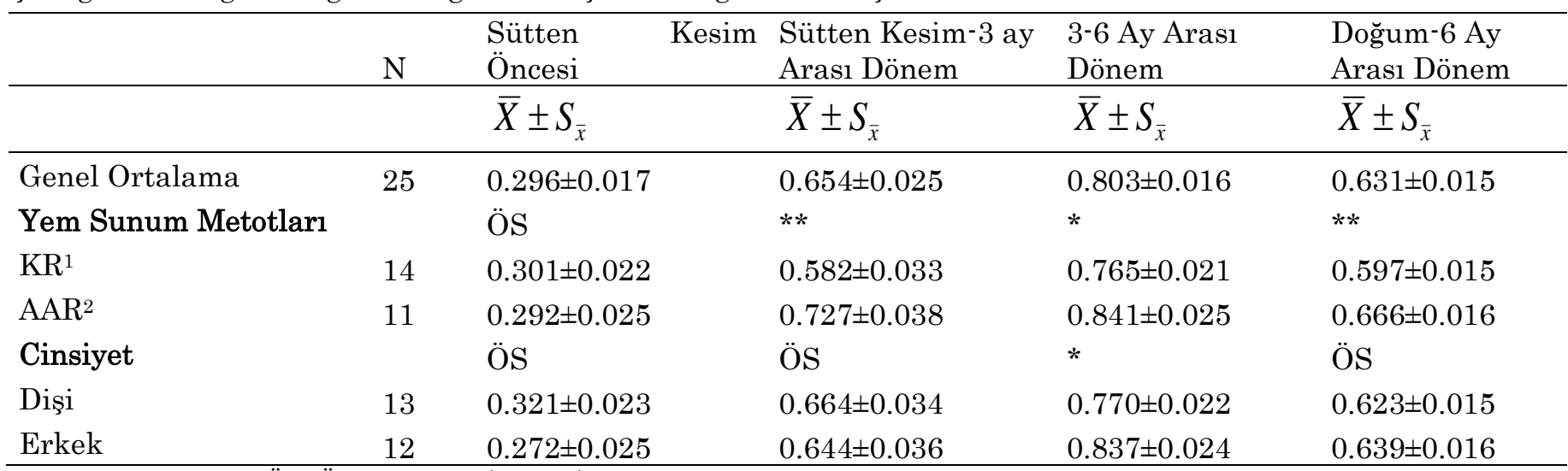

${ }^{*} \mathrm{P}<0.05,{ }^{* *} \mathrm{P}<0.01$, ÖS: Önemli değil (P>0.05). ${ }^{1} \mathrm{KR}:$ Kıyılmış kaba yem ile kesif yemin karıştırılarak aynı yemlikte sunumu.

${ }^{2} \mathrm{AAR}$ : Doğal formda kaba yemin, kesif yem ile karıştırılmadan ayrı yemliklerde sunumu.

Sütten kesim sonrası dönemde ise, canlı ağırlık artışları bakımından önemli farklılıklar tespit edilmiştir. AAR grubunda bulunan buzağgların günlük ağırlık artış değerleri KR grubundakilere göre sütten kesim-3 ay arasinda \% $24.9(\mathrm{P}<0.01), 3-6$ ay arasinda \% $9.9(\mathrm{P}<0.05)$ ve doğum-6 ay arasında \% $11.5(\mathrm{P}<0.01)$ daha yüksek bulunmuştur. Benzer yönde Kincaid (1980) kaba yemin doğal formda yedirildiği buzağıların 12 haftalık deneme süresince \% 16 oranında daha fazla canlı ağırlık artışı sağladıklarını rapor etmişlerdir. Atwood ve ark. (2001)'de karışı rasyon alan buzağıların canlı ağırlık artışlarının, kaba ve kesif yemlerin ayrı yemliklerde sunulduğu gruba göre daha yavaş olduğunu bildirmişlerdir. Öte yandan, Nissanka ve ark., (2010) buzağılara kıyılmış kaba yemle kesif yemin karıştırılarak sunulduğunda kaba ve kesif yemi ayrı alan gruba göre daha yüksek günlük canlı ağırlık artışı yaptığını bildirmişlerdir.

Cinsiyet grupları açısından incelendiğinde, 3-6 ay arası dönemde erkek buzağılar, dişilerden \% 8.7 daha fazla $(\mathrm{P}<0.05)$ ağırlık kazandıkları saptanmıştır. $\mathrm{Bu}$ sonuç, Turgut ve ark., (1997) ile uyum içerisinde olup 
erkek buzağıların dişi buzağılara göre önemli derecede yüksek $\quad(\mathrm{P}<0.05)$ günlük canlı ağırlık artışı (\% 8) yaptıklarını bildirmişlerdir.

KR ve AAR gruplarındaki erkek ve dişi buzağılarca tüketilen yem miktarlarına (kuru madde cinsinden) ait en küçük kareler ortalamaları ile standart hataları Çizelge 4'te sunulmuştur. Yem tüketimi bakımından sütten kesim öncesi $(\mathrm{P}<0.05)$ ve sütten kesim sonrası $(\mathrm{P}<0.01)$ dönemlerde yem sunum grupları (KR ve AAR) arasında istatistiksel olarak önemli farklılıklar tespit edilmiştir. AAR grubundaki buzağıların KR grubundakilere göre toplam yem tüketimi daha fazla olmuştur. Bu farklılıklar sütten kesim öncesi \% 15.9, sütten kesim-3 ay arası \% 18.5, 3-6 ay arası \% 14.2, doğum- 6 ay arasında ise \% 18.1 olarak saptanmıştır. Benzer şekilde, Turgut ve ark., (1997) kıyılmış formda kuru çayır otu ile yemlenen buzağıların doğal formda kaba yem alan gruba göre, sütten kesim6 aylık yaş döneminde önemli derecede $(\mathrm{P}<0.05)$ daha az miktarda yem alımı yaptıklarını rapor etmişlerdir. Karışık rasyonlarla beslenen süt ırkı buzağıların yem tüketim miktarlarının önemli ölçüde azaldığı DeVires ve von Keyserlingk (2009) ve Miller-Cushon ve ark., (2013) tarafından da saptanmıştır. Paralel bulgular Iraira ve ark., (2012) tarafindan da bildirilmiş olup, kesif ve kaba yemin ayrı yemliklerde verildiği ortalama 114 baş Sarı Alaca dişi dananın günlük canlı ağırlık artışlarının, bu yemlerin karıştırılarak bir yemlikte sunulan hayvanlara nazaran önemli derecede $(\mathrm{P}<0.05)$ fazla olduğu saptanmıştır.

Büyümenin farklı devrelerinde cinsiyet grupları arasında yem tüketimi açısından istatistiksel anlamda önemli bir fark belirlenememiş olup, bu sonucun
Turgut ve ark., (1997)'nın bulgulariyla uyum içerisinde olduğu saptanmıştır.

Deneme gruplarında $1 \mathrm{~kg}$ ağırlık artışı için tüketilen yem miktarları Çizelge 5'te sunulmuştur. Yemden yararlanma değerlerine bakıldığında tüm deneme süresi içinde yemden yararlanma bakımından gruplar arasinda istatistiksel olarak önemli bir farklılık gözlenmemiştir. KR grubundaki yüksek canlı ağırlık artışı ve yüksek yem tüketiminin sonucunda yemden yararlanma dereceleri her iki deneme grubunda benzer olarak bulunmuştur. $\mathrm{Bu}$ sonucun Iraira ve ark., (2012)'nın bulguları ile de uyum içersinde olduğu saptanmıştır. Benzer şekilde, Hill ve ark., (2010), 56 gün süre ile yürütülen bir çalışmada, kıyılmıs ot ile doğal formda kuru çayır otu ve kesif yem alan buzağılarda yemden yararlanma değerleri arasında önemli bir fark bulunmadığını rapor etmişlerdir.

Altı aylık dönemde, büyümenin diğer bir göstergesi olan buzağıların çeşitli vücut ölçülerinde sağlanan artışlara ait en küçük kareler ortalamaları ile standart hataları Çizelge 6'da sunulmuştur.

Muamele grupları arasında göğüs derinliği $(3.1 \mathrm{~cm})$ ve göğüs çevresinde $(4.3 \mathrm{~cm})$ AAR lehine önemli $(\mathrm{P}<0.05)$ farklılıklar saptanmıştır. Genel olarak incelendiğinde, vücut ölçülerindeki artışlar bakımından AAR grubundaki buzağıların, KR grubuna göre 6 aylık periyotta vücut ölçülerinde rakamsal olarak nispeten daha fazla bir gelişme sağladığı belirlenmiştir. Hill ve ark., (2010)'da vücut ölçülerindeki artış bakımından, kıyılmış veya natürel formda kaba yem alan deneme grupları arasında önemli bir fark tespit edememişlerdir.

Çizelge 4. Buzağılarda tüketilen yem miktarlarına $(\mathrm{kg})$ ait en küçük kareler ortalamaları ve standart hataları

\begin{tabular}{|c|c|c|c|c|c|}
\hline & $\mathrm{N}$ & $\begin{array}{ll}\text { Sütten } & \text { Kesim } \\
\text { Öncesi } & \\
\end{array}$ & $\begin{array}{ll}\text { Sütten } & \text { Kesim-3 } \\
\text { Ay Arası Dönem }\end{array}$ & $\begin{array}{l}-6 \quad \text { Ay Arası } \\
\text { Dönem }\end{array}$ & $\begin{array}{ll}\text { Doğum-6 Ay } & \text { Arası Dönem } \\
\text { Aras }\end{array}$ \\
\hline & & $\bar{X} \pm S_{\bar{x}}$ & $\bar{X} \pm S_{\bar{x}}$ & $\bar{X} \pm S_{\bar{x}}$ & $\bar{X} \pm S_{\bar{x}}$ \\
\hline Genel Ortalama & 25 & $30.45 \pm 1.09$ & $80.48 \pm 2.12$ & $323.16 \pm 5.57$ & $437.09 \pm 12.04$ \\
\hline Yem Sunum Metotları & & * & $* *$ & $* *$ & $* *$ \\
\hline $\mathrm{KR}^{1}$ & 14 & $28.21 \pm 1.46$ & $73.68 \pm 2.82$ & $301.79 \pm 6.76$ & $400.77 \pm 16.04$ \\
\hline $\mathrm{AAR}^{2}$ & 11 & $32.69 \pm 1.66$ & $87.29 \pm 3.22$ & $344.53 \pm 7.71$ & $473.41 \pm 18.30$ \\
\hline Cinsiyet & & NS & NS & NS & NS \\
\hline Dişi & 13 & $31.06 \pm 1.51$ & $82.62 \pm 2.92$ & $319.96 \pm 6.99$ & $424.74 \pm 16.58$ \\
\hline Erkek & 12 & $29.84 \pm 1.61$ & $78.34 \pm 3.12$ & $326.36 \pm 7.46$ & $449.44 \pm 17.71$ \\
\hline
\end{tabular}

${ }^{*} \mathrm{P}<0.05,{ }^{* *} \mathrm{P}<0.01$, ÖS: Önemli değil (P>0.05). ${ }^{1} \mathrm{KR}:$ Kıyılmış kaba yem ile kesif yemin karıştırılarak aynı yemlikte sunumu.

${ }^{2} \mathrm{AAR}$ : Doğal formda kaba yemin, kesif yem ile karıştırılmadan ayrı yemliklerde sunumu. 
Çizelge 5. Buzağılarda $1 \mathrm{~kg}$ ağırlık artışı için tüketilen yem miktarlarına ait en küçük kareler ortalamaları ve standart hataları

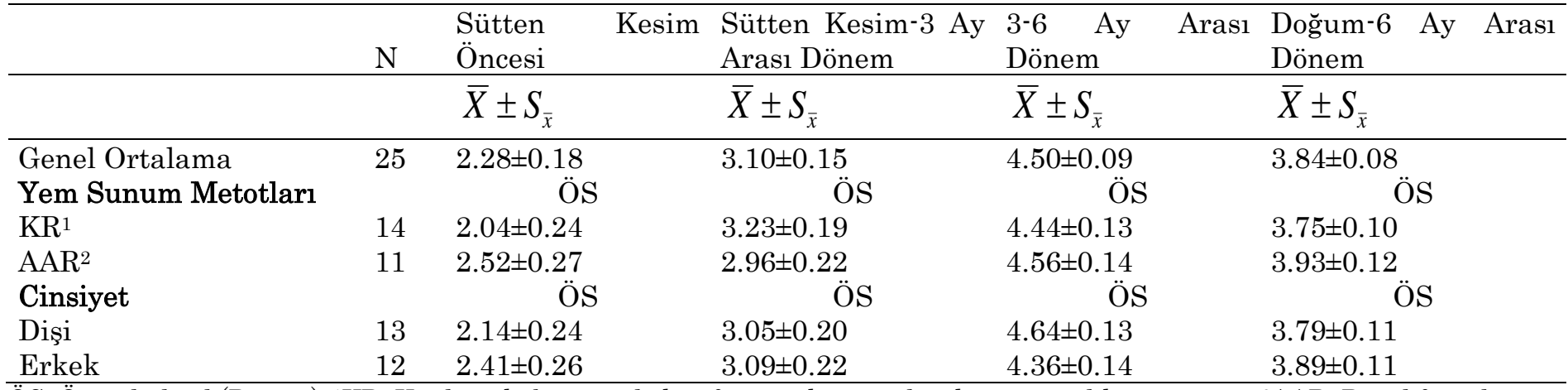

ÖS: Önemli değil (P>0.05). ${ }^{1} \mathrm{KR}$ : Kıyılmış kaba yem ile kesif yemin karıştırılarak aynı yemlikte sunumu. ${ }^{2} \mathrm{AAR}$ : Doğal formda kaba yemin, kesif yem ile karıştırılmadan ayrı yemliklerde sunumu.

Çizelge 6. Buzağılarda doğum 6 ay arası vücut ölçülerindeki artışlara $(\mathrm{cm})$ ait en küçük kareler ortalamaları ve standart hataları

\begin{tabular}{lcccccc}
\hline & $\mathrm{N}$ & $\begin{array}{l}\text { Vücut } \\
\text { Uzunluğu }\end{array}$ & $\begin{array}{l}\text { Cidago } \\
\text { Yüksekliği }\end{array}$ & $\begin{array}{l}\text { Göğüs } \\
\text { Derinliği }\end{array}$ & $\begin{array}{l}\text { Göğüs } \\
\text { Cevresi }\end{array}$ & $\begin{array}{l}\text { Ön İncik } \\
\text { Cevresi }\end{array}$ \\
\hline & & $\bar{X} \pm S_{\bar{x}}$ & $\bar{X} \pm S_{\bar{x}}$ & $\bar{X} \pm S_{\bar{x}}$ & $\bar{X} \pm S_{\bar{x}}$ & $\bar{X} \pm S_{\bar{x}}$ \\
\hline Genel Ortalama & 25 & $32.4 \pm 0.9$ & $26.4 \pm 1.0$ & $13.8 \pm 0.6$ & $45.1 \pm 1.1$ & $3.3 \pm 0.2$ \\
Yem Sunum Metotları & & ÖS & ÖS & $*$ & $*$ & ÖS \\
KR 1 & 14 & $31.0 \pm 1.2$ & $24.8 \pm 1.2$ & $12.3 \pm 0.8$ & $42.9 \pm 1.4$ & $3.3 \pm 0.2$ \\
$\mathrm{AAR}^{2}$ & 11 & $33.8 \pm 1.4$ & $28.0 \pm 1.4$ & $15.4 \pm 0.9$ & $47.2 \pm 1.7$ & $3.3 \pm 0.3$ \\
Cinsiyet & & $*$ & ÖS & ÖS & ÖS & ÖS \\
Dişi & 13 & $34.3 \pm 1.2$ & $28.0 \pm 1.2$ & $14.4 \pm 0.8$ & $45.3 \pm 1.4$ & $3.0 \pm 0.2$ \\
Erkek & 12 & $30.5 \pm 1.4$ & $24.8 \pm 1.4$ & $13.3 \pm 0.9$ & $44.8 \pm 1.7$ & $3.5 \pm 0.3$ \\
\hline
\end{tabular}

${ }^{*} \mathrm{P}<0.05$, ÖS: Önemli değil (P>0.05). ${ }^{1} \mathrm{KR}:$ Kıyılmış kaba yem ile kesif yemin karıştırılarak aynı yemlikte sunumu. ${ }^{2} \mathrm{AAR}$ :

Doğal formda kaba yemin, kesif yem ile karıştırılmadan ayrı yemliklerde sunumu.

Buzağılarda doğum-6 ay arası tespit edilen davranış özelliklerine ait sonuçlar Şekil 1'de sunulmuştur. Buzağılık dönemi süresince farklı yem sunumları ile yemlenen buzağılar arasında ayakta durma, yem yeme $(\mathrm{P}<0,01)$ ve su içme davranışlarında önemli $(\mathrm{P}<0,05)$ farklılıklar saptanmıştır. AAR grubundaki buzağılar, KR grubundakilere göre günlük \% 19.0 oranında daha sık yem yeme, \% 46.7 oranında da daha sık su içme davranışları gösterdikleri saptanmıştır. Bu sonuçlar, Çizelge 4 te sunulan söz konusu grubun yüksek yem tüketimini değerlerini açılayan bir bulgu mahiyetindedir. Benzer sonuç, Greter ve ark. (2010) tarafindan da bildirilmiş olup yemlemeyi takip eden zaman dilimi içersinde, orjinal formda sunulan kaba yemle birlikte kesif yemin, kıyılmış kuru ot ve kesif yem karışım rasyonuna göre daha uzun süre buzağılarda yem yeme davranışına neden olduğu rapor edilmiştir. Miller-Cushon ve ark., (2013) da yem dağıtımının yapıldığı saatte KR grubundaki buzağıların, yem yeme için, kaba ve kesif yemlerin ayrı ayrı sunulduğu buzağılara göre daha az zaman harcadıklarını bildirmişlerdir. Öte yandan, buzağılara ait bulguların aksine, düvelerde ve ineklerde karışık rasyonlarla beslenmenin bu hayvanlarda yem yeme davranışlarında bir artışa neden olduğu Maekawa ve ark., (2002) ile DeVires ve von Keyserlingk (2009) tarafından da ifade edilmiştir. Ayrıca, KR grubundaki buzağıların günün önemli bir kısmını ayakta geçirirken, AAR grubundakiler daha ziyade yatma davranışı sergilemişlerdir. Bu sonuçun Iraira ve ark., (2012)'nın bulgularıyla uyum içerisinde olduğu görülmüştür.

\section{SONUÇ}

$\mathrm{Bu}$ çalışmada kaba yemlerle kesif yemlerin ayrı yemliklerde sunulmasının Siyah Alaca buzağıların 3 ve 6. aylarda saptanan canlı ağırlıkları ile sütten kesim sonrası canlı ağırlık artışları üzerine pozitif yönde önemli etki yaptığı, yem tüketimini artırırken yemden yararlanma derecesi üzerine olumsuz etki yapmadığı da tespit edilmiştir. Ayrıca doğal formdaki kaba yem ile kesif yemin karıştırılmadan verilmesinin yem yeme, su içme gibi beslenmeye yönelik davranışların görülme sıklığında bir artışa, ayakta durma davranışında da azalmaya neden olduğu saptanmıştır. Sonuç olarak, Siyah Alaca buzağılara kaba yemlerin doğal formuyla ve kesif yemden ayrı olarak sunulmasının daha uygun olacağ kanaatine varılmıştır. 


\section{Doğum-6 ay}

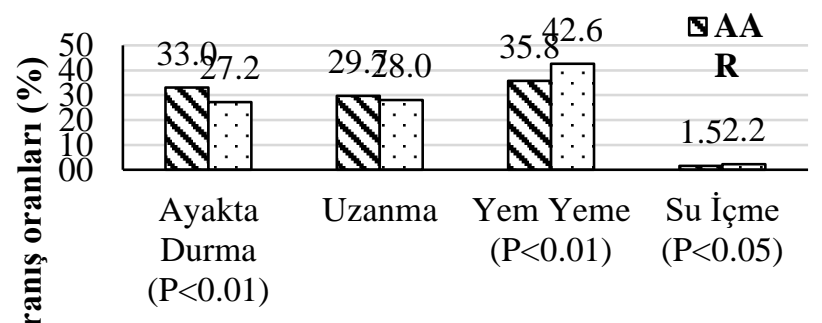

\section{Davranış özellikleri}

Şekil 1. Buzağılarda doğum-6 ay arası davranış özellikleri

\section{KAYNAKLAR}

Atwood SB, Provenza FD, Wiedmeier RD, Banner RE 2001. Influence of Free-Choice vs Mixed-Ration Diets on Food Intake and Performance of Fattening Calves. Journal of Animal Science, 79: 3034-3040.

Bakır G. Demirel M 2001. Van İli ve İlçelerindeki Sığırcılık İşletmelerinde Kullanılan Yem Çeşitleri ve Hayvan Besleme Alışkanlıkları. Yüzüncü Yıl Üniversitesi Ziraat Fakültesi Tarım Bilimleri Dergisi, 11(1): 29-37.

Beharka AA, Nagaraja TG, Morrill JL, Kennedy GA, Klemm, RD 1998. Effect of Form of Diet on Anatomical Microbial and Fermantative Development of The Rumen Neonatal Calves. Journal of Dairy Science, 81:1946-1955.

Chua B, Coenen E, Delen J, Weary DM 2002. Effects of Pairy Versus Individual Housing on The Behaviour and Performance of Dairy Calves. Journal of Dairy Science, 85:360- 364.

Coverdale JA, Tyler HD, Quigley JD, Brumm JA 2004. Effect of Various Levels of Forage and Form of Diet on Rumen Development and Growth in Calves. Journal of Dairy Science, 87: 2554-2562.

DeVires TJ, von Keyserlingk MA G 2009. Feeding Method Affects The Feding Behavior of Growing Dairy Heifers. Journal of Dairy Science, 92:11611168.

Diler A, Koçyiğit R, Yanar M, Aydın R, Güler O, Avcı M 2016. Erzurum İli Hınıs İlçesi Sığırcılık İşletmelerinde Sığır Besleme Uygulamaları Üzerine Bir Araştırma. Anadolu Tarım Bilim. Derg. Anadolu Journal of Agricultural Sciences, 31(1):149-156.

Greter AM, Leslie KE, Mason GJ, McBride BW, DeVries TJ 2010. Effect of Feed Delivery Method on The Behavior and Growth of Dairy Heifers. Journal of Dairy Science, 93: 1668-1676.

Güler O, Yanar M, Bayram B 2003. Effect of Different Milk Feeding Schedules on the Growth and Feed Conversion Efficiencies in Holstein Friesian and
Brown Swiss Calves. Indian Journal of Animal Science, 73(11):1278-1280.

Hassani MW, Görgülü M, Göncü S 2017. Effect of Choice Feeding in The Pre-Weaning Period on The Growth Performance of Calves During The Pre- and Post-Weaning Periods. Asian Research Journal of Agriculture, 5(1): 1-8.

Hill TM, Bateman HG, Aldrich JM, Schlotterbeck RL 2010. Roughage Amount, Source, and Processing for Diets Fed to Weaned Dairy Calves. The Professional Animal Scientist, 26:181-187.

Hozman SB 2014. Sivas İli Damızlı Siğır Yetiştiricileri Birliğine Üye Süt Sığırcılı̆̆ İşletmelerinde Hayvan Besleme Uygulamaları. Aydın Adnan Menderes Üniversitesi, Fen Bilimleri Enstitüsü, Zootekni Anabilim Dalı, Yüksek Lisans Tezi, $144 \mathrm{~s}$.

Hunter L, Houpt KA 1989. Bedding Material Preferences of Ponies. Journal of Animal Science, 67:1986- 1991.

Iraira S, Ruíz de la Torre J, Rodríguez-Prado M, Manteca X, Calsamiglia S, Ferret A 2012. Effect of Feeding Method on Intake and Behaviour of Individually Reared Beef Heifers Fed Concantrate Diet from 115 to $185 \mathrm{~kg}$ of Body Weight. Animal, $6: 1483-1490$.

Kincaid RL 1980. Alternate Methods of Feeding Alfalfa to Calves. Journal of Dairy Science, 63: 91-94.

Krause KM, Oetzel GR 2006. Understanding and Preventing Subacute Ruminal Acidosis in Dairy Herds: A review. Animal Feed Science and Technology, 126: 215-236.

Martin P, Bateson P 1993. Measuring Behaviour. Cambridge: Cambridge University Press.

Maekawa M, Beauchemin KA, Christensen DA 2002. Effect of Concentrates Level and Feeding Management on Chewing Activities, Saliva Production and Ruminal $\mathrm{pH}$ of Lactating Dairy Cows. Journal of Dairy Science, 85:1165 -1175.

Miller-Cushon EK, Bergeron R, Leslie KE,Mason GJ, DeVries TJ 2013. Effect of Early Exposure to Different Feed Presentations on Feed Sorting of Dairy Calves. Journal of Dairy Science, 96(7): 46244633.

Montoro C, Miller-Cushon EK, DeVries TJ, Bach A 2013. Effect of Physical Form of Forage on Performance, Feeding Behavior, and Digestibility of Holstein Calves. Journal of Dairy Science, 96(2): 1117-1124.

Nissanka N, Bandara R, Disnaka K 2010. A Comparative Study on Feeding of Total Mixed Ration vs Conventional Feeding on Weight Gain in Weaned Friesian Heifers Under Tropical Environment. Journal of Agricultural Sciences, 5(1):42-51.

Özlütürk A, Yanar M, Tüzemen N, Kopuzlu S 2006. Calving and Preweaning Growth Performance Traits of Calves Sired by Charolais, Simmental and 
Eastern Anatolian Red Bulls. Turkish Journal of Veterinary and Animal Sciences, 30: 257-263.

Plaza J, Martínez Y, Ibalmea R 2009. Roughage Handling in The Feeding of Reposition Female Calves. Cuban Journal of Agricultural Science, 43(1): 17-19.

SPSS (2004). SPSS 13.0 for Windows, Release 13.0. SPSS Inc. Chicago, Il., USA.
Turgut L, Yanar M, Tüzemen N, 1997. Kaba Yem Formunun Esmer Buzağılarda Büyüme ve Yemden Yararlanma Özelliklerine Etkileri. Ondokuz Mayıs Üniversitesi Ziraat Fakültesi Dergisi, 12 (3):11-22. Vasseur E, Borderas F, Cue RI, Lefebvre D, Pellerin D, Rushen J, Wade KM, de Passillé AM 2010. A Survey of Dairy Calf Management Practices in Canada that Affect Animal Welfare. Journal of Dairy Science, 93:1307-1315. 